\title{
Implementation of Kangaroo Mother care for low birth weight babies: supportive factors and barriers perceived by mothers
}

\author{
Mekle $D^{1}$, Patil $\mathbf{R}^{2}$, Jha $\mathbf{P}^{3}$ \\ ${ }^{1}$ Dr. Dinesh Mekle, Assistant Professor, ${ }^{2}$ Dr. Rajesh Patil, Assistant Professor, ${ }^{3}$ Pratibha Jha, MBBS Student, all authors \\ are affiliated with Department of Paediatrics, Peoples College of Medical Sciences \& Research Centre, Bhanpur, Bhopal, \\ MP, India.
}

Corresponding Author: Dr. Rajesh Patil, MD., Assistant Professor, Department of Paediatrics, PCMS \& RC, Bhanpur, Bhopal. E-mail: drrajeshpediapg@gmail.com

\begin{abstract}
Introduction: Kangaroo mother care (KMC) consist of prolonged skin to skin contact between mother and infant and exclusive breastfeeding. It was originally developed to prevent hypothermia and to enhance bonding between mother and Infant. Methods: It was a questionnaire based cross sectional observational study. Questionnaire was prepared by authors in local native language and was validated by experts; mothers with babies fit for KMC were enrolled and interviewed with a predefined proforma having both open and close ended questions with their demographic details. Results: More than half (54\%) of the mothers had no knowledge about KMC during their pregnancy. About $46 \%$ of them were made aware by their doctors $(82.6 \%)$ or their relatives (mother/elder sisters). Most mothers get help from nursing staff (98\%) and they felt that environment was conducive for the practice of $\mathrm{KMC}(70 \%)$ and they got help from other mothers $(74 \%)$ and family members $(84 \%)$. Barriers were pain due to stitches $(44 \%)$, unfavorable condition to perform KMC (29.4\%), fatigue/fear while performing KMC (16.3\%), difficulty due to twins $(9.8 \%)$. Pain/fatigue $(53.75 \%)$ is the barrier to KMC according to the mothers; about $30 \%$ mothers felt temperature as a barrier while practicing KMC. Conclusion: They believed that their babies will become healthier and can feed easier after initiation of KMC. Inspiration from family members or other mothers are also an enabler of KMC. Lack of support from family members, other mothers as well as from nursing staff in some cases, this barrier can be improved by training of their family members.
\end{abstract}

Keywords: Barriers, Breast feeding, Kangaroo Mother Care, Low birth weight

\section{Introduction}

World health organisation defines kangaroo mother care as $\mathrm{KMC}$ consist of prolonged skin to skin contact between mother and infant, exclusive breastfeeding whenever possible [1]. KMC was originally developed to prevent hypothermia in infants, promote exclusive breastfeeding and to strengthen the mother-infant bonding. $\mathrm{KMC}$ is an evidence-based approach to reduce mortality and morbidity in preterm and LBW infants $[2,3]$.

Among newborns who were clinically stable, kangaroo mother care reduces mortality and if widely practiced it helps in weight gain could reduce deaths in preterm newborns [4]. KMC is steadily increasing in high-tech settings due to its proven benefits for both infants and mothers [5]. KMC can be started in hospital and if

Manuscript received: $6^{\text {th }}$ February 2018

Reviewed: $16^{\text {th }}$ February 2018

Author Corrected: $24^{\text {th }}$ February 2018

Accepted for Publication: $28^{\text {th }}$ February 2018 necessary, and continued at home, for as long as the infant needs it for temperature control, which can be up to term age. To adequately implement and effectively scale-up this intervention it is critical to understand the key factors that contribute to a mother's ability/inability to practice KMC. However inspite of the evidences and adoption, implementation of KMC has been limited and global coverage remains low.

Therefore, this study was planned at a tertiary care teaching hospital in central India to assess the supportive factors and barriers perceived by mothers during implementation of $\mathrm{KMC}$.

\section{Objectives}

To find out the factors supporting initiation and practice of $\mathrm{KMC}$ and to find out the barriers perceived by mothers to implement and continue KMC. 


\section{Methodology}

This was a Questionnaire based cross sectional observational study that was conducted in department of pediatrics of a teaching hospital in central India, catering predominantly urban slums. During this study period once the babies were fit for KMC his/her mother was enrolled in the study after taking the written informed consent.

Enrolled mothers were sensitized about the advantages of $\mathrm{KMC}$ by one to one talk and audiovisual aids. After 3 days of KMC practice mothers were interviewed with the help of a predefined proforma having both open and close ended questions with their demographic details. Questionnaire was in native language which was easily understandable to the mothers. Appropriate statistical methods were applied and analysis was done. Study was started after getting approval from institutional ethical committee.

Inclusion criteria: Mothers of babies with birth weight $<2.5 \mathrm{~kg}$ requiring admission in NICU or Step down nursery and gave consent for enrollment in the study.

Exclusion Criteria: Mothers who didn't follow KMC practices for at least 3 days. Primary outcome to be measured: To identify supportive factors and barriers for practicing $\mathrm{KMC}$ as perceived by mothers of low birth weight babies. Statistical analysis Data were analyzed using relevant statistical tests after cleaning and coding.

\section{Result}

Among 50 mothers interviewed their mean age was 24.8 years $(\mathrm{SD}=2.82)$ and mean gestational age was 33.5 weeks $(\mathrm{SD}=2.00)$. Their babies sex ratio was almost equal. Majority of delivery done was normal (60\%) Many of them belong to joint family (68\%) having income more than Rs 5000/month (72\%) and reside in the urban locality (62\%). Most of the mothers completed their education up to higher secondary (78\%) [Table-1].

Table-1: Demographic characteristics of mothers interviewed in the study.

\begin{tabular}{|c|c|c|c|}
\hline & & Number $(\mathbf{N}=\mathbf{5 0})$ & $\%$ \\
\hline \multirow[t]{2}{*}{ 1. Gender of the baby } & Female & 22 & 44 \\
\hline & Male & 28 & 56 \\
\hline \multirow[t]{2}{*}{ 2. Type of delivery } & Normal & 30 & 60 \\
\hline & Caesarean section & 20 & 40 \\
\hline \multirow[t]{2}{*}{ 3. Type of family } & Nuclear & 16 & 32 \\
\hline & Joint & 34 & 68 \\
\hline \multirow[t]{2}{*}{ 4. Income } & $<5000$ rs & 14 & 28 \\
\hline & $>5000 \mathrm{rs}$ & 36 & 72 \\
\hline \multirow[t]{2}{*}{ 5. Residency } & Urban & 31 & 62 \\
\hline & Rural & 19 & 38 \\
\hline \multirow[t]{6}{*}{ 6. Mother's education } & Illiterate & 0 & 0 \\
\hline & Primary & 9 & 18 \\
\hline & High school & 12 & 24 \\
\hline & Higher secondary & 18 & 36 \\
\hline & Graduate & 10 & 20 \\
\hline & Post graduate & 1 & 2 \\
\hline \multirow{3}{*}{ 7. Type of feeding } & Mother's milk & 41 & 82 \\
\hline & Formula milk & 3 & 6 \\
\hline & Mixed & 6 & 12 \\
\hline
\end{tabular}

Majority of the mothers feed their own milk to the baby (82\%). Most of the mothers started practicing KMC when their babies were $<7$ days (44\%). Total duration of KMC per day was between 2 to $4 \mathrm{hrs}(62 \%)$, and duration per sitting were 1-2hrs. None of them performed KMC during nights [Table-2]. 
Editorial

Table-2: Practice of KMC.

\begin{tabular}{|l|c|c|c|}
\hline & Duration & $\mathbf{N}=\mathbf{5 0}$ & $\mathbf{\%}$ \\
\hline \multirow{3}{*}{ 1. when KMC was started(days) } & $<7$ days & 22 & 44 \\
\cline { 2 - 4 } & $7-14$ days & 25 & 50 \\
\cline { 2 - 4 } & $>14$ days & 3 & 6 \\
\hline \multirow{2}{*}{ 2. Total duration of KMC done per day } & $1-<2 \mathrm{hrs}$ & 12 & 24 \\
\cline { 2 - 4 } & $2-4 \mathrm{hrs}$ & 31 & 14 \\
\hline \multirow{2}{*}{ 3. Duration of KMC done per sitting } & $>4 \mathrm{hrs}$ & 7 & 44 \\
\cline { 2 - 4 } & $<1 \mathrm{hr}$ & 22 & 56 \\
\hline \multirow{2}{*}{ 4. Performance of KMC during nights } & $>1 \mathrm{hr}$ & 28 & 0 \\
\cline { 2 - 4 } & Yes & 0 & 100 \\
\hline
\end{tabular}

More than half (54\%) of the mothers had no knowledge about KMC during their pregnancy. About $46 \%$ of them were made aware by their doctors $(82.6 \%)$ or their relatives (mother/elder sisters). Majority of them got help from nursing staff $(98 \%)$ and they felt that environment was conducive for the practice of KMC $(70 \%)$ and they got help from other mothers $(74 \%)$ and their family members $(84 \%)$ [table-3].

Table-3: Factors promoting initiation/inhibition of performance of KMC.

\begin{tabular}{|c|c|c|c|}
\hline & & Number $(n=50)$ & $\%$ \\
\hline \multirow[t]{2}{*}{ 1. Knowledge about KMC during pregnancy } & Yes & 23 & 46 \\
\hline & No & 27 & 54 \\
\hline \multirow[t]{2}{*}{ Knowledge given by } & Doctors & 19 & 82.6 \\
\hline & Others (family members) & 4 & 21.7 \\
\hline \multirow[t]{2}{*}{ 2. Did mother get help from nursing staff } & Yes & 48 & 96 \\
\hline & No & 2 & 4 \\
\hline \multirow[t]{2}{*}{ 3. Is environment conducive for $\mathrm{KMC}$} & Yes & 35 & 70 \\
\hline & No & 15 & 30 \\
\hline \multirow[t]{2}{*}{ 4. Did mother get help from other mothers } & Yes & 37 & 74 \\
\hline & No & 13 & 26 \\
\hline \multirow{2}{*}{$\begin{array}{l}\text { 5. Did mother get help from other family } \\
\text { members }\end{array}$} & Yes & 42 & 84 \\
\hline & No & 8 & 16 \\
\hline
\end{tabular}

Mothers perceived that KMC practice made them feel more attached towards the baby (48.75\%), they believed that baby will become healthier (24.39\%), they can feed easily while doing KMC (23.17) and baby temperature is maintained throughout the practice of KMC (4.8\%). They felt pain in the stitches, fatigue, hot and humid climate and difficulty while practicing KMC acted as the barriers [Table-4].

Table-4: Perception of mothers to KMC.

\begin{tabular}{|c|c|c|c|}
\hline \multirow{2}{*}{$\begin{array}{c}\text { Why KMC is } \\
\text { important for you }\end{array}$} & I felt more attached to baby & Number (N=50) & 24 \\
\cline { 2 - 4 } & I felt baby will become healthy sooner (gain weight) & 12 & 24.75 \\
\cline { 2 - 4 } & I could feed easily and much more amount of milk started \\
& to come & 11 & 23.17 \\
\cline { 2 - 4 } & Baby's temperature is maintained & 3 & 4.8 \\
\hline \multirow{2}{*}{$\begin{array}{c}\text { What are the } \\
\text { barriers during } \\
\text { performance of } \\
\text { KMC }\end{array}$} & Pain due to stitches (LSCS/episiotomy) & 22 & 44.26 \\
\cline { 2 - 4 } & Uncomfortable environment (hot and humid) & 15 & 29.4 \\
\cline { 2 - 4 } & Number(N=50) & 16.3 \\
\hline
\end{tabular}


By interviewing 50 mothers we found that majority of mothers (92\%) felt good after practicing KMC, many of them disagreed that their workload increased by doing $\mathrm{KMC}(78 \%)$ and their knowledge about KMC is enhanced after the training (88\%). They felt that more milk has started to come while practicing KMC. Many of them (56\%) declined that practicing KMC can cause injury either to their babies (56\%) or to their stitches (64\%) [Table-5].

Table-5. Likert scale.

\begin{tabular}{|c|c|c|c|}
\hline Perception & Response & $\mathbf{N}$ & $\%$ \\
\hline \multirow[t]{5}{*}{ Mothers felt good after doing KMC } & Strongly disagree & 0 & 0 \\
\hline & Disagree & 2 & 4 \\
\hline & Neutral & 2 & 4 \\
\hline & Agree & 33 & 66 \\
\hline & Strongly agree & 13 & 26 \\
\hline \multirow{5}{*}{$\begin{array}{l}\text { Mothers' workload is increased due to } \\
\text { KMC }\end{array}$} & Strongly disagree & 8 & 16 \\
\hline & Disagree & 25 & 50 \\
\hline & Neutral & 6 & 12 \\
\hline & Agree & 11 & 22 \\
\hline & Strongly agree & 0 & 0 \\
\hline \multirow{5}{*}{$\begin{array}{l}\text { There is an enhancement of the } \\
\text { knowledge of mothers after KMC }\end{array}$} & Strongly disagree & 0 & 0 \\
\hline & Disagree & 0 & 0 \\
\hline & Neutral & 6 & 12 \\
\hline & Agree & 27 & 54 \\
\hline & Strongly agree & 17 & 34 \\
\hline \multirow{5}{*}{$\begin{array}{c}\text { More milk has started to come after } \\
\text { doing KMC }\end{array}$} & Strongly disagree & 0 & 0 \\
\hline & Disagree & 6 & 12 \\
\hline & Neutral & 16 & 32 \\
\hline & Agree & 15 & 30 \\
\hline & Strongly agree & 13 & 26 \\
\hline \multirow{5}{*}{$\begin{array}{l}\text { Mothers felt that KMC can cause } \\
\text { injury to the baby }\end{array}$} & Strongly disagree & 8 & 16 \\
\hline & Disagree & 20 & 40 \\
\hline & Neutral & 8 & 16 \\
\hline & Agree & 14 & 28 \\
\hline & Strongly agree & 0 & 0 \\
\hline \multirow{5}{*}{$\begin{array}{l}\text { Mothers felt that KMC can cause } \\
\text { injury to their stitches } \\
\text { (LSCS/episiotomy) }\end{array}$} & Strongly disagree & 15 & 30 \\
\hline & Disagree & 17 & 34 \\
\hline & Neutral & 3 & 6 \\
\hline & Agree & 13 & 26 \\
\hline & Strongly agree & 2 & 4 \\
\hline
\end{tabular}

\section{Discussion}

In the present study, most important factor promoting initiation of $\mathrm{KMC}$ is the attachment with infants $\mathrm{KMC}$ $(48.75 \%)$ which is quite similar and comparable to other studies [2,6]. Such percentage can be increased by proper counselling of expectant mother and family members. About $24.39 \%$ of mothers believed that their baby will become healthier and will gain weight that is found to be true in several studies and had better effect on daily weight gain [7]. Better and easier breastfeeding is a good enabler of $\mathrm{KMC}$ according to $23.17 \%$ of the mothers. Various researchers showed a significant positive effect on early breastfeeding and its duration. Studies have been reported that KMC had a greater positive effect on success rate than first breastfeeding itself [9]. Some mothers also believed that the baby's temperature is also maintained while practicing $\mathrm{KMC}$. Proper warmth and temperature is provided by skin to skin contact with the babies. The results are comparable about the mothers perception on babies temperature regulation by $\mathrm{KMC}$ in other studies $[10,11,12]$. 
Other factors supporting initiation of KMC are support from family members other mothers of the hospital, help of the nursing staff and knowledge about the KMC during pregnancy which was quite similar to study by Seidman et al., in which support from the family is one of the top five enablers of KMC (72\%) [13,14,15].

Apart from these many factors such as attachment with the baby, easier feeding, hope of becoming healthier, sooner discharge from the hospital, inspiration from mothers and doctors helped to enable the KMC.

There are certain barriers that mothers faced during $\mathrm{KMC}$ are pain due to stitches (44\%), unfavorable condition to perform KMC (29.4\%), fatigue/fear while performing KMC (16.3\%), difficulty due to twins $(9.8 \%)$. Pain/fatigue $(53.75 \%)$ is the fourth barrier to KMC according to the mothers, about $30 \%$ mothers felt temperature as a barrier while practicing KMC. The barriers are quite comparable to few studies $[16,17,18]$.

Other barriers include lack of knowledge about KMC, lack of support given to the mothers by their family members $(26 \%)$, by other mothers in the ward $(36 \%)$, nursing staff (4\%) which was quite similar as per Smith et al., study in which $24 \%$ mothers felt, lack of help with KMC practice and other obligations as a barrier.

These barriers were identified too in available published literature [19]. Hot and humid climate is also one of the barrier for $\mathrm{KMC}$ that can be ruled out by making a separate $\mathrm{KMC}$ room that will maintain the temperature as well as privacy of the mother.

Difficulty in practicing $\mathrm{KMC}$ due to twins can be overcome by counselling their family members and by teaching them to perform $\mathrm{KMC}$ among themselves similarly pain due to stitches can be decreased by several counselling to the mother and showing them proper method to perform KMC. Anti-natal knowledge about the KMC is also one of effective ways to initiate KMC.

\section{Conclusion}

Factors supporting initiation of KMC are that mothers felt more attachment, calm and happier after KMC. They believed that their babies will become healthier and can feed easier after initiation of KMC. Inspiration from family members or other mothers are also an enabler of KMC.

Present study concludes that the lack of knowledge during pregnancy is one of the reason behind lack of practice of KMC. Other reasons include lack of support from their family members, other mothers as well as from nursing staff in some cases, that can be improved. Lack of support/promotion from family members is also an important barrier for the mother that can be improved by training of their family members.

\section{Authors Contribution:}

Dr Dinesh Mekle: Questionnaire preparation, Study design, Data entry monitoring. Dr Rajesh Patil: Questionnaire preparation, Manuscript preparation, Data analysis. Pratibha Jha: Data collection and entry, educating the mothers

\section{What this study adds:}

There is paucity of literature available on KMC practices in central India about how mothers perceived KMC. What are the common problems faced while practicing KMC. This study adds the knowledge of mothers about perception and barriers of KMC practice in central part of India.

\section{Abbreviations}

KMC: Kangaroo Mother Care, LBW: Low Birth Weight, NICU: Neonatal Intensive Care Unit, LSCS: Lower Segment Caesarean Section

Funding: Nil, Conflict of interest: None initiated, Perission from IRB: Yes

\section{References}

1. Geneva. World Health Organisation.A practical guide Kangaroo mother care. 2003.

2. Seidman G, Unnikrishnan S, Kenny E, Myslinki S, Cairns-Smith S, Mulligan B, et al., Barriers and Enablers of Kangaroo Mother Care Practice: A Systematic Review. PLoS One. 2015 May 20; 10 (5): e 0125643. doi: 10.1371/ journal. pone. 0125643.e Collection 2015

3. Conde-Agudelo A, Diaz-Rossello JL. Kangaroo mother care to reduce morbidity and mortality in low birth weight infants. Cochrane Database Syst Rev. 2014 Apr 22; (4): CD002771. doi: 10.1002/ 14651 858. CD002771.

4. Grace J Chan, Amy S Labar, StephenWall, Rifat Atun. Kangaroo mother care: a systematic review of barriers and enablers. Bulletin of the World Health Organization 2016; 94:130-141J.

doi: http://dx.doi.org/10. 2471/BLT.15.157818. 
Editorial

5. Stikes R Barbier D. Applying the plan -do-study -act model to increase the use of kangaroo care. J Nurs Manag. 2013. January; 21 (21) :70-78 .10.1111/jonm. 12021.

6. Gathwala G, Singh B, Singh J:Effect of kangaroo mother care on physical growth, breast feeding and its acceptability. Trop Doct. 2010 Oct;40(4):199-202. doi: 10.1258/td.2010.090513. Epub 2010 Jul 28. PubMed PMID: 20667921.

7. Mehboobeh N, Sedigheh T, Majid M, Fatemesadat M. the implementation of kangaroo mother care and nurses perspective of barriers in Iranian NICUs. Iran J Nurs Midwifery Res. 2016 Jan-Feb; 21(1): 84-88. doi: $10.4103 / 1735-9066.174753$

8. Samuel et al. Perception and practice of Kangaroo mother care after discharge from hospital in Kumasi, Ghana: A longitudinal study. BMC Pregnancy and Childbirth 2011:99 https://doi.org/10.1186/1471-239311-99.

9. Brimdyr K, Widstrom AM, Cadwell K, Svensson K, Turner-Maffei C. A Realistic Evaluation of Two Training Programs on Implementing Skin-to-Skin as a Standard of Care. J Perinat Educ. 2012 Summer; 21(3): 149-157.doi: 10.1891/1058-1243.21.3.149

10. Feldman R, Weller A, Sirota L, Eidelman AI. Testing a family intervention hypothesis: the contribution of mother-infant skin-to-skin contact (kangaroo care) to family interaction, proximity, and touch. JFam Psychol 2003, 17: 94-107

11. Mohammed El-Nagger NSAEA H, Mahmoud Zaki Hassan S. Effect of kangaroo mother care on premature infants' physiological, behavioral, and psychosocial outcomes in Ain Shams maternity and Gynecological Hospital,Cairo,Egypt.LifeScienceJournal2013:703-716.

12. Bazzano A, Hill Z, Tawiah-Agyemang C, Manu A, ten Asbroek G, Kirkwood B. Introducing home based skin-to-skin care for low birth weight newborns: a pilot approach to education and counseling in Ghana. Global health promotion 2012, 19: 42-49.

13. Bigelow A, Power M, MacLellan-Peters J, Alex M, Mc Donald C. Effect of mother/ infant skin-to skin contact on postpartum depressive symptoms and maternal physiological stress. J Obstet Gynecol Neonatal Nurs. 2012 May-Jun; 41(3):369-82. doi: 10. 1111/j. 1552-6909.2012.01350.

14. Parmar VR, Kumar A, Kaur R, Parmar S, Kaur D, Basu $\mathrm{S}$, et al. Experience with kangaroo mother care in a neonatal intensive care unit (NICU) in Chandigarh, India. Indian J Pediatr. 2009 Jan;76(1):25-8. doi: 10. 1007/s 12098-009-0024-2

15. Solomons N, Rosant C. Knowledge and attitudes of nursing staff and mothers towards kangaroo mother care in the eastern sub-district of Cape Town. South African Journal of Clinical Nutrition 25(1):33-39. January 2012 with1, 170 Reads. DOI:10.1080/ 16070658. 2012. 11734400 .

16. Lima G, Quintero-Romero S, Cattaneo A. Feasibility, acceptability and cost of kangaroo mother care in Recife, Brazil. Ann Trop Paediatr. 2000 Mar;20 (1): $22-6$

17. Kambarami RA, Mutambirwa J, Maramba PP. Caregivers' perceptions and experiences of 'kangaroo care' in a developing country. Trop Doct $2002 \mathrm{Jul}$; 32(3):131-3.

18. Charpak N, Ruiz-Pelaez JG. Resistance to implementing Kangaroo Mother Care in developing countries, and proposed solutions. Acta Paediatr 2006 May; 95 (5):529-34.

19. Johnson AN. Factors influencing implementation of kangaroo holding in a Special Care Nursery. MCN Am J Matern Child Nurs. 2007. Jan-feb;32(1):25-9.

\section{How to cite this article?}

Mekle D, Patil R, Jha P. Implementation of Kangaroo Mother care for low birth weight babies: supportive factors and barriers perceived by mothers. Int J Pediatr Res. 2018;5(2):87-92. doi:10.17511/ijpr.2018.i02.08. 